\title{
Subject-independent modeling and representation data on the formation and distribution of innovative value
}

\author{
Aleksey Frolov ${ }^{1}$ and Irina Maslova,"* \\ ${ }^{1}$ Orel State University, Department of software engineering, 302020, Orel, Russia \\ ${ }^{2}$ Orel State University, Department of economic security, 302020, Orel, Russia
}

\begin{abstract}
Creating an innovation environment is shown in the context of interaction of economic agents in the creation and consumption of innovative value-based infrastructure approach. The problem of the complexity of collecting heterogeneous data on the formation and distribution of innovative value in the conditions of the dynamic nature of the research object and the environment is formulated. An information model providing a subject-independent representation of data on innovation value flows is proposed and allows to automate the processes of data collection and analysis with the minimization of time costs. The article was prepared in the course of carrying out research work within the framework of the project part of the state task in the field of scientific activity in accordance with the assignment 26.2758.2017 / 4.6 for 2017-2019. on the topic "System for analyzing the formation and distribution of the value of innovative products based on the infrastructure concept".
\end{abstract}

\section{Introduction}

For modern economic development, financial instruments are needed, more flexible, maneuverable and stimulating the innovation process than those used in the traditional economy.

According to official statistics, in the Russian Federation, the cost of technological innovation in 2015 was $1,200,363.8$ million rubles [22].

The analysis of the dynamics of organizations engaged in innovative activity in the Russian Federation shows that in 2015 only $9.3 \%$ ( $0.6 \%$ less than in 2014) of the organizations surveyed engaged in innovative activity. At the same time, the share of organizations that carried out technological innovation was $8.3 \%$ (against $8.8 \%$ in 2014) [22].

Traditionally in the Russian Federation, as in many countries of the world, the state was the most significant source of funding for science and innovation. However, recently in western countries there has been a decrease in the share of public financing due to the increase in the share of the private corporate sector against the background of the strengthening of indirect stimulation of innovation processes (tax breaks, concessional lending, support of innovative business).

For private investors, the possibility of obtaining transparent and reliable information on the formation of value added of innovative products and its market actualization is of particular importance.

\section{Literature review}

Among the classics of economic theory laying the methodological foundation of the theory of value and the mechanism of pricing, it is necessary to name
O. Bem-Bawerka, J. Gelbright, J. Debreu, JM Keynes, V. Leontiev, K. Marx, A. Marshall, B. Petty, A. Pigou, D. Ricardo, J. Robinson, A. Smith, I. Schumpeter, P. Samuelson, L. Thurow, M. Friedman, I. Fischer, J. Hicks, and others.

Domestic economists also made a significant contribution to the development of the theory of value, value, the mechanism of pricing and valuation, the most outstanding among them: L.I. Abalkin, V.M. Ageev, V.A. Bazarov, K.K. Walthuh, A.S. Gusarov, V.P. Dyachenko, L.V. Kontorovich, I.D. Kondratiev, I.K. Larionov, B.C. Nemchinov, A.V. Novichkov, N.S. Perekalina, K.N. Plotnikov, V.T. Smirnov, S.G. Strumilin, N.P. Fedorenko, P.N. Shulyak, Yu.V. Yakovets and others.

In the field of international financial reporting standards, the following works are noteworthy: D. Alexander, A. Britton, H. Grüning, E. Jorissen, M. Cohen, Karsberg B. Mikerin G. et al.

The problems of controlling the structural dynamics of complex systems are reflected in the works of BV Sokolov, RM Yusupova. and other researchers of the St. Petersburg Institute of Informatics and Automation of the Russian Academy of Sciences.

The following researchers consider modeling and creating adaptive and adaptive software based on relevant information models: Cangussu J. W., Miller S. D., Cai K., Mathur A. P., C. Dellarocas, M. Klein, H. Shrobe, P. Oreizyetal, J. Palsberg, C. Xiao, and K. Lieberherr, Y. Diao, J.L. Hellerstein, S. Parekh, R. Griffith, G.E. Kaiser и др.

\footnotetext{
*Corresponding author: tera_27@mail.ru
} 


\section{Hypotheses and methods of research}

In the process of research, collection and processing of information, classical empirical and theoretical methods of research were used: study of literature, observation, survey, monitoring, generalization of experience, dialectical method, hypothesis construction, proof, analysis, synthesis, comparison, abstraction, concretization, generalization, induction, deduction, analogy, modeling, system approach.

\section{Results of the study}

Innovative activity of the enterprise is a system of measures, united in a logical chain. Scientific research, experimental design and technical development, innovative, financial, commercial and industrial activities are subject to the same goal - the creation and implementation of innovations. Innovative activity is characterized by frontality, high level of uncertainty and risk, complexity of forecasting results, requires taking into account the time factor at different stages of the innovation process.

The process of creating innovations is associated with the costs of labor and material resources and as a result, like any productive process, leads to the formation of socially useful value embodied in innovative products.

Now in Russia at the state level (administrative and public infrastructure) prerequisites for a civilized process of creating innovations are created. The existing state regulation and support of the intellectual market should nevertheless be improved at all levels of the innovative macro-climate, affecting the internal innovation environment of the enterprise.

In the innovation process, the time factor plays a big role, since a significant amount of time can pass between the innovation and the release of an innovative product on its basis. Thus, the degree of readiness of the result of the scientific and innovative process to commercialization is important. Market actualization of value - bringing the value in line with the state of the economic environment through commercial transactions, expressed in the purchase by the buyer of natural media of value and the formation of the seller of the monetary equivalent of value [11] (figure 1).

In accordance with the Methodology for Determining the Levels of Technology Preparedness within the Framework of the Projects of the Federal Targeted Program "Research and Development in Priority Areas for the Development of the Scientific and Technological Complex of Russia for 2014-2020", the following ranges of funding are allocated at the expense of the state target program (figure 2) [18].

\section{Creating value-added innovative product}

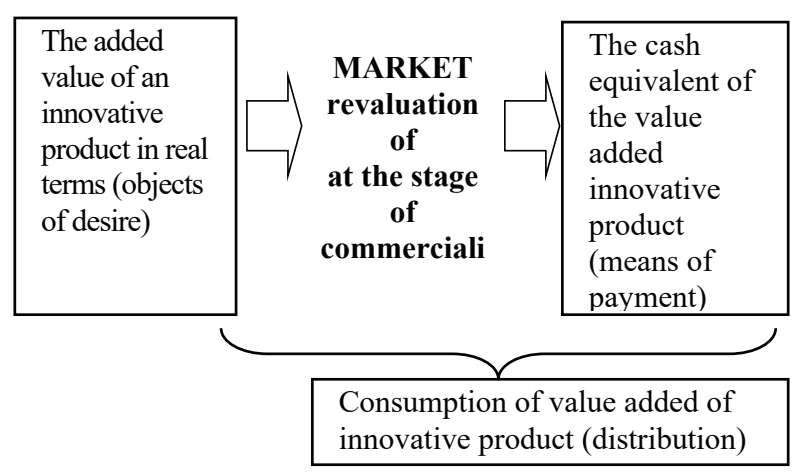

Fig. 1. Market's actualization of the added value of an innovative product

The level of readiness of the technology for the types of scientific and technical/production activities

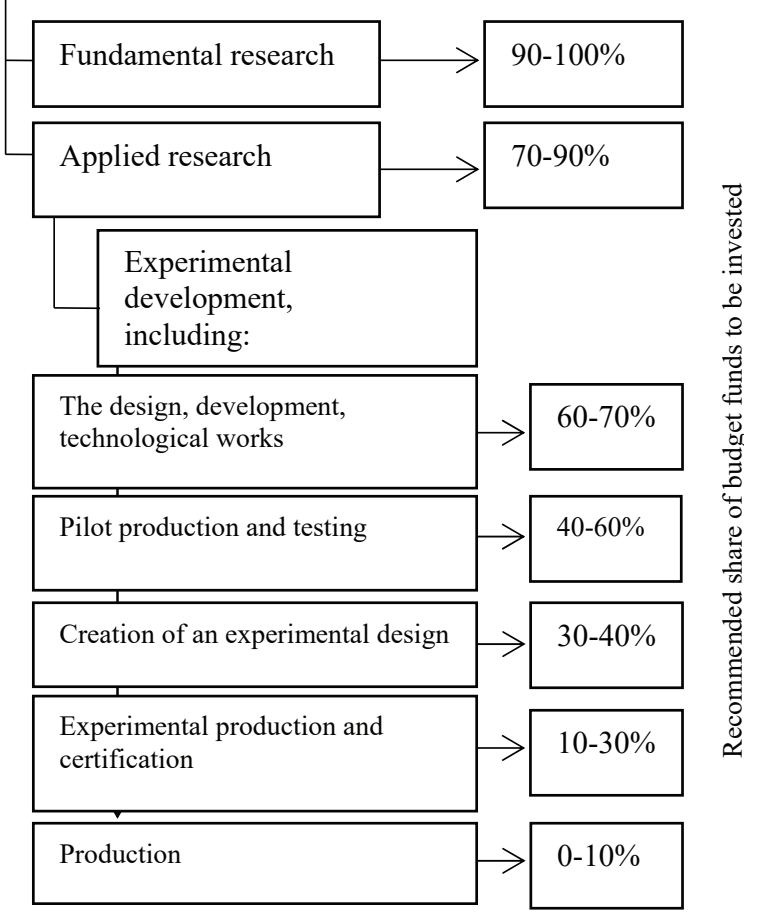

Fig. 2. Potential share of budgetary funds in the cost of innovation, depending on the level of availability of technology

The current practice in Russia of reflecting the cost of innovative products in the accounting and analytical registers of enterprises is characterized by the lack of integrity of the results of the compilation of accounting data from the point of view of carrier uniformity and by type of value, which makes it difficult to reliably estimate innovative value and innovative value added (created and actualized on the market).

Innovation activity has a significant impact on all aspects of financial and economic activity, requires the investment of own and borrowed funds in significant amounts and therefore, transparent information on the flow of innovative value should be reported. However, 
in the accounting reporting there are no such concepts as innovations and objects of innovative activity taking into account its stages of a full life cycle.

IFRS regulates the accounting and reporting of revenues, expenses, assets and liabilities, providing a factual information base for making managerial decisions at all levels. The relationship between the national multi-level accounting system and IFRS is shown in the figure 3 .

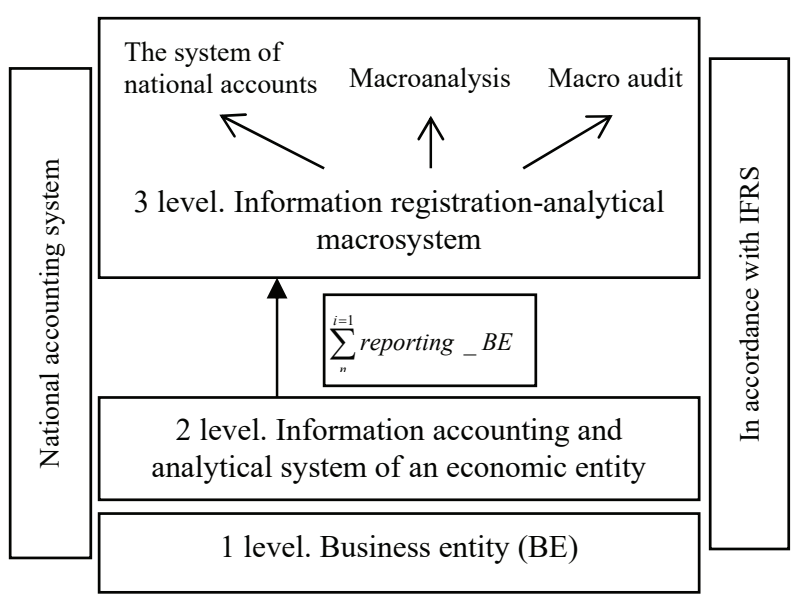

Fig. 3. Interrelation of the accounting and analytical system of an economic entity with an accounting and analytical macro system in the national accounting system in accordance with the transition to IFRS.

The complexity of accounting and analytical processes requires the use of modern tools for collecting, storing and analyzing data. And when considering each specific implementation of the accounting and analytical process, the structure and composition of the system of indicators varies. The reasons for this can be the dynamism of both the accounting object itself, which is a complex system, and the environment. In the works $[5,6,7,17]$, "formalization and research of a new class of applied problems, namely, problems of managing the structural dynamics" of technical and organizationaltechnical systems (OTS) was carried out. According to their works, structural dynamics can manifest themselves in the form of the following processes:

- changes in the ways, purposes of functioning of the OTS, their content, sequence of implementation;

- movement in the space of individual elements of the OTS;

- redistribution and decentralization of functions, tasks, control algorithms, information flows between management levels;

- management of reserves;

- Reconfiguration of OTS structures in case of its degradation.

Data collection under such conditions is usually called monitoring. The type of monitoring, involving the prompt collection of information on the state of the control object from various sources (manual data entry by the operator, import from the databases of the MRP/ERP subsystems) will be called administrative. The implementation of new specialized or modification of existing software for data collection and storage in such cases is inefficient due to their one-time use or use a small number of times. At the same time, the emerging time costs do not allow the operative solution of the assigned task.

Thus, it becomes urgent to use the system of administrative monitoring, which provides an adaptive organization of data collection and data storage processes, that is, a process-oriented system built on the basis of the software accounting and analytical activity that is adaptable to the task. Studies in the field of software adaptation are reflected the works $[8,13,14,20$, 21,23,24,]. They address the choice of architecture for adaptive software, the development of control algorithms for adaptive software; about quality criteria for the evaluation of adaptive software.

This report proposes an approach to structural adaptation, based on a two-level abstraction of the information model of the accounting object. The proposed data storage model provides an invariant representation of the accounting object and flexible customization when requirements for the data collection and storage procedure change [19].

Data on the types of accounting objects arrive at the input of the system at the stage of adaptation of the monitoring system to the requirements of accounting and analytical processes (see Figure 4).

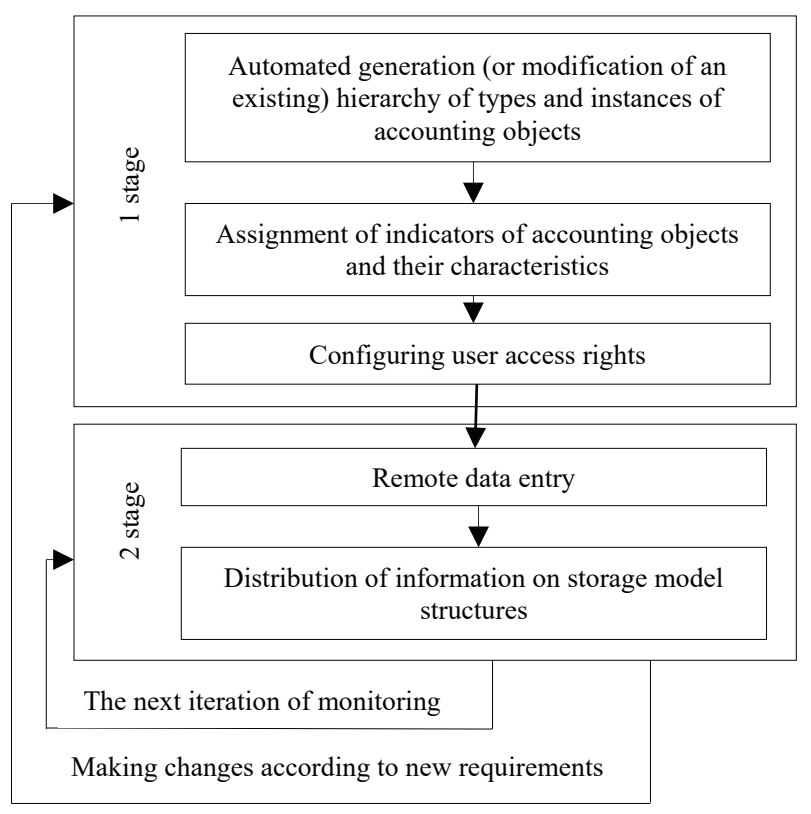

Fig. 4. General methodology of organization of processes collection and storage of data

Since the monitoring system supports not only linear connectivity of the types of accounting objects, but also the network type, the input types are structured. That is, each newly entered type of accounting object is assigned possible types of parents and possible types of descendants. The set of types forms the input set $\mathrm{Vt}$.

A set of parent type relationships is expressed by a subset of the Cartesian product 


$$
\mathrm{Vtx} \mathrm{Vt}: \mathrm{Et}=\{(\mathrm{t} 1, \mathrm{t} 2) \mid(\mathrm{t} 1 \sqsubset \mathrm{Vt}) \&(\mathrm{t} 2 \sqsubset \mathrm{Vt})\} .
$$

Accounting objects (AO) are compared to the types of accounting objects in many respects because of the need to conduct different monitoring of them, tracing changes or current states for certain sets of indicators. For this, certain sets are mapped to sets of indicators. It is for these sets of indicators that all monitoring objects of this type will be monitored. We denote the set of all indices entering the input of the system P. Then the set of all possible sets of exponents:

$$
2 \mathrm{P}=\{\mathrm{XP} \mid \mathrm{XP} \subset \mathrm{P}\}
$$

Then Rtp $\subset 2 \mathrm{P} \times \mathrm{Vt}$, represents the indicators inherent in each type of accounting object. This relation can be represented as a mapping from the Boolean $2 \mathrm{P}$ to the set Vt: Rtp $=\left\{(X P, t) \mid X P \sqsubset P \& t F_{V t}\right\}$.

Data on instances of accounting objects are entered at the stage of filling in the model of links of instances of accounting objects.

Data processing of this type includes the generation of hierarchical and network links between the added and existing instances, the control of the correspondence between the format of the model object to be added to the accounting object, the control of the authorization of changes in the structure of the links of the objects of the accounting objects.

Eto - the object typing relation. The element of this relation is an instance of the op-amp with its associated type $(t, o)$. Such typed instances are linked in pairs by the "child-parent" relationship, thus creating ordered pairs of elements of the set Eto. The model of object links:

$$
\begin{gathered}
\mathrm{Eo}=\{(\text { Eto1, Eto2 }) \mid E t 1=(\mathrm{t} 1, \mathrm{t} 2) \& \text { Eto1 }=(\mathrm{o} 1, \mathrm{t} 1) \& \\
\text { Eto2 }=(02, \mathrm{t} 2) .
\end{gathered}
$$

That is, typed AO Eto1 is a descendant of a typed copy Eto2 if there is a pair «type- descendant $\rightarrow$ typeparent » Et1 $=(t 1, t 2)$ such that in a pair Eto1 to a copy o1 mapped type t1, and in a pair Eto2 to a copy o2 mapped type $\mathrm{t} 2$. The relation Eo can be represented by an array of arcs of the graph.

Elementary unit of the dialog input interface is a mathematical object that is associated with some instance of the accounting object and an indicator whose value will be entered into the system. The ratio of typed accounting objects to the sets of indicators for which monitoring is conducted: Eto ${ }^{\circ} \mathrm{Rtp}$ :

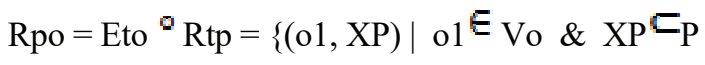

$$
\begin{aligned}
& \exists_{\mathrm{t}} \in_{\mathrm{Vt}} \text { o1Etot \& tRtpXP\}. }
\end{aligned}
$$

Each element of this relation represents a set of interface elements for registering the values of the indicators of a certain accounting object. Thus, the element of the relation is the ordered pair of an instance of the accounting object 01 and its associated set of indicators $\mathrm{XP}, \mathrm{o} 1 \in_{\mathrm{Vo}} \& \mathrm{XP} \subset_{\mathrm{P}}$, provided there is a certain type of accounting object from a set of types such that the ratio Eto can map an instance of o1 to type $t$ and the ratio Rtp can be obtained from type $t$ associated with it XP.

This ratio allows us to describe the set of generated input interfaces for registering the values of the metering object indicators, which is the result of the adaptation of the monitoring system to the monitoring task.

Each implementation of the introductory interface for an accounting object instance for the input of indicator values is represented by the function $\mathrm{i}(\mathrm{O}, \mathrm{Xp})$ from the arguments: an instance of the accounting object and a set of indicators by which the values are registered. In the case of using indicators with a limited general population of possible values, the model expands. Each indicator of this type is associated with a set of possible values from a set of values available for input to users of the system, which is expressed by the ratio:

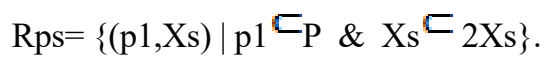

Then the composition of relations Rpo $=$ Eto ${ }^{\circ}$ Rtp will change to Rvpo $=\mathrm{Eto}^{\circ} \mathrm{R}$ tps, where Rtps - the ratio of the accounting object to the set of indicators with a limited general population of values, and will be compiled with the participation of the Rps ratio defined above instead of $\mathrm{P}$ in one of its components:

$$
\begin{gathered}
\operatorname{Rtps}=\left\{(\operatorname{Rps} 1, \mathrm{t} 1) \mid \operatorname{Rps} 1 \subset_{\mathrm{Rps}} \& \mathrm{t} 1 \in_{\mathrm{Vt}}\right\} \text { (6) } \\
\mathrm{Rvpo}=\mathrm{Eto}^{\circ}{ }^{\circ} \mathrm{Rtps}=\left\{(\mathrm{o} 1, \mathrm{Rps} 1) \mid \mathrm{o} 1 \in_{\mathrm{Vo}} \& \mathrm{Rps} 1\right. \\
\left.\square_{\mathrm{Rps}} \exists_{\mathrm{t}} \in_{\mathrm{Vt}} \text { o1Etot \& tRtpRps } 1\right\}
\end{gathered}
$$

Thus, the element of the relation is the ordered pair of an instance of the accounting object ol and its associated set of indicators, each of which is associated with a set of possible values of Rps1, provided there is a certain type of accounting object from a set of types such that the ratio Eto can map an instance of o1 to type $\mathrm{t}$ and the relation Rtp it is possible to obtain from the type $t$ the indicators associated with it with associated sets of possible values.

When working in the indicator values monitoring mode, the registered value of the indicator $\mathrm{v}$ Vs ( $\mathrm{Vs}$ - the set of indicator values) is compared to the interface element (i). The interface element model is an element of the relationship between typed accounting objects and sets of indicators. Let us express this with the attitude:

$$
\text { Rspo }=\left\{(\mathrm{i}, \mathrm{v}) \mid\left(\mathrm{i} \beth_{\mathrm{Rpo} \| \mathrm{i}} \simeq_{\mathrm{Rvpo}) \& \mathrm{v}} \in_{\mathrm{Vs}\}} .\right.\right.
$$

The information is entered into the monitoring system in two modes:

- mode of preparation (adaptation) of the system to a specific accounting and analytical process;

- a mode of collection of values of indicators of objects of the account. 
At present, practical implementation of adaptable data storage structures and data collection interfaces has been carried out. The prototype of the system is tested on particular tasks.

\section{Conclusions}

The report presents elements of the concept of constructing an accounting and analytical system of innovation value by the stages of its formation and distribution of value added. Methodological model of accounting, analysis and control of innovative value is presented on the example of own sources of financing of the innovation process.

Practical implementation of operational accounting of innovative value is faced with technological limitations, due to the complexity, including the dynamic nature of the research object and environmental factors.

The proposed subject-independent model for presenting data on the formation and distribution of innovation value, based on two-level abstraction, provides the ability to quickly adapt the data collection and storage system to changing conditions.

The implementation of the subsystem for the collection and storage of data in the form of a subsystem in the accounting and analytical system will make it possible to fully and effectively implement the proposed approach to the accounting and analysis of the flow of the value of an innovative product.

\section{References}

1. A.S. Alisenov, Tax stimulation of innovations in the Russian economy: monograph. (Prospekt, Moscow, 2015)

2. A. Pelin, K. Kala, EUROPEAN ECONOMIC REVIEW, 91, 89-117 (2017)

3. A. Amrein-Beardsley, M. Pivovarova, T. J. Geiger, PHI DELTA KAPPAN, 98, Iss. 2, 35-40 (2016)

4. B.G. Maslov, Management Accounting, No. 11, 2329 (2009)

5. B.V. Sokolov, E.G. Tsivirko, R.M. Yusupov, Proceedings of SPIIRAS., Iss. 11, 11-49 (2009)

6. B.V. Sokolov, R.M. Yusupov, Problems of Control and Computer Science, No. 5, 24-41 (2002)

7. B.V. Sokolov, R.M. Yusupov, Sat. sci. tr. Intern. sci. School "Modeling and analysis of safety and risk in complex systems (IADB-2008)", 146-155 (2008)

8. C. Dellarocas, M. Klein, and H. Shrobe. In Proc. The Third International Software Architecture Workshop, 29-32 (1998)

9. Caraballo, Jose G ; Jiang, Xiao Value-Added, JOURNAL OF ECONOMIC ISSUES, 50, Iss. 1, 288-296 (2016)

10. E.G. Dedkova, Management accounting, No. 10., 70-76. (2011)
11. I.A. Maslova, Managerial Accounting, No. 1, 17$25,(2016)$

12. I.A. Maslova, Finance and credit, №4 (2006)

13. J. Palsberg, C. Xiao, and K. Lieberherr, ACM Transactions on Programming Languages and Systems, 17 (2), 264-292 (1995)

14. J. W. Cangussu, K. Cooper, and C. Li, In Proc. of the 19th Annual ACM Symposium on Applied Computing (March 2004).

15. L.V. Popova I.A. Maslova, B.G. Maslov, Actual problems of economy, №6, 390-402 (2015)

16. Lind, C. Holmstrom, Kang, Olivia H., Management international review, 57, Iss.4, 571-602 (2017)

17. M.Yu. Okhtilev, B.V. Sokolov, R.M. Yusupov, Intellectual technologies for monitoring and managing the structural dynamics of complex technical objects ( Nauka, Moscow, 2006)

18. Methodology for determining the levels of technology readiness in the framework of the projects of the federal special-purpose program "Research and development in priority areas of development of the scientific and technological complex of Russia for 2014-2020" [Electronic resource] / Access mode: http://fcpir.ru/upload/ medialibrary / 955 / gt_57_14vn_metodika-ugt_002_.pdf

19. N.A. Kravtsova, Automation of the processes of data collection and storage during administrative monitoring: Dis .... kand. ... cand. those. sciences. Eagle., 164 with. (2012)

20. P. Lin, A. MacArthur, and J. Leaney, In Proc. The 2005 Australian Software Engineering Conference. IEEE Computer Society (2005).

21. P. Oreizyetal, IEEE Intell. Syst., 54-62 (1999)

22. Science and innovation, access mode: http://www.gks.ru/wps/wcm/connect/rosstat_main/r osstat/ru/statistics/science_and_innovations/science /\#

23. J. W. Cangussu, S.D. Miller, K. Cai, and A. P. Mathur, Software Cybernetics, Encyclopedia of Computer Science and Engineering, John Wiley \& Sons, 4, 2575 - 2583 (2009).

24. Y. Diao, J. L. Hellerstein, S. Parekh, R. Griffith, G. E. Kaiser, and D. Phung, IEEE J. Sel. Areas Commun., 23 (12): 2213-2222 (2005). 